\section{Mucosal tears and colonic perforation in a patient with collagenous colitis}

Collagenous colitis, which is clinically characterized by chronic non-bloody diarrhea, is a variant of microscopic colitis. It can be diagnosed on histological grounds, with thickening of the subepithelial collagen layer [1-3]. The colonic mucosa is usually endoscopically normal, although minor abnormalities such as edema or erythema can be seen $[2,3]$. Serious complications are rare.

A 69-year-old woman was referred to us with non-bloody diarrhea. Fecal analysis showed trophozoites of Dientamoeba fragilis, but treatment with metronidazole did not improve the diarrhea.

She underwent colonoscopy, which revealed a diffuse erythematous colon with small, white longitudinal linear ulcerations ( Fig.1 a,b). On insufflation spontaneous longitudinal mucosal tears appeared ( $\bullet$ Fig.1c); while the mucosa was being biopsied, large portions of it came away effortlessly. Therefore, no further examination was undertaken at this stage. Histopathological assessment subsequently showed thickening of the subepithelial collagen layer, consistent with collagenous colitis.

After the procedure the patient developed acute abdominal pain. Plain radiography revealed free air. She underwent a laparotomy, during which no perforation was identified and an ileostomy was created. After treatment with budesonide, the patient made a full recovery and 4 months later, a reversal of the ileostomy was performed.

Collagenous colitis is increasingly recognized as a cause of chronic non-bloody diarrhea. The exact etiology remains unknown, but several factors may play a role. For example, $40 \%$ of patients have an autoimmune disease, such as celiac disease or thyroiditis, suggesting an autoimmune component. Other factors reported as being involved include luminal factors, dietary antigens, several medications, bacterial toxins, dysfunction of myofibroblasts, and bile salts $[2,3]$.

The clinical course of collagenous colitis is usually benign and the colon often appears endoscopically normal. Serious complications, such as mucosal tearing or perforation, are extremely rare [4-8]; the exact frequency of this complication being unknown, but probably less than $1 \%$.

It is important to recognize that mucosal tears during insufflation are a sign of collagenous colitis. Further endoscopic examination should not be performed, in order to prevent more damage and perforations.

\section{Endoscopy_UCTN_Code_CPL_1AJ_2AH}

\section{Competing interests: None}

\section{Rachel L. A. van Eijk, Dirk Jan Bac}

Department of Gastroenterology and Hepatology, The Gelderse Vallei Hospital, Ede, The Netherlands

\section{References}

1 Tangri V, Chande N. Microscopic colitis: an update. J Clin Gastroenterol 2009; 43: 293 296

2 Williams JJ, Beck PL, Andrews CN et al. Microscopic colitis - a common cause of diarrhoea in older adults. Age Ageing 2010; 39: $162-$ 168

3 Pardi DS, Kelly CP. Microscopic colitis. Gastroenterology 2011; 140: 1155-1165

4 Sherman A, Ackert JJ, Rajapaksa $R$ et al. Fractured colon: an endoscopically distinctive lesion associated with colonic perforation following colonoscopy in patients with collagenous colitis. Clin Gastroenterol 2004; 38: $341-345$

5 Cruz-Correa M, Milligan F, Giardiello FM et al. Collagenous colitis with mucosal tears on endoscopic insufflation: a unique presentation. Gut 2002; 51: 600

6 Wickbom A, Lindqvist M, Bohr J et al. Colonic mucosal tears in collagenous colitis. Scand J Gastroenterol 2006; 41: 726-729

7 Bohr J, Larsson LG, Eriksson S et al. Colonic perforation in collagenous colitis: an unusual complication. Eur J Gastroenterol Hepatol 2005; 17: 121-124

8 Freeman HJ, James D, Mahoney CJ. Spontaneous peritonitis from perforation of the colon in collagenous colitis. Can J Gastroenterol 2001; 15: $265-267$
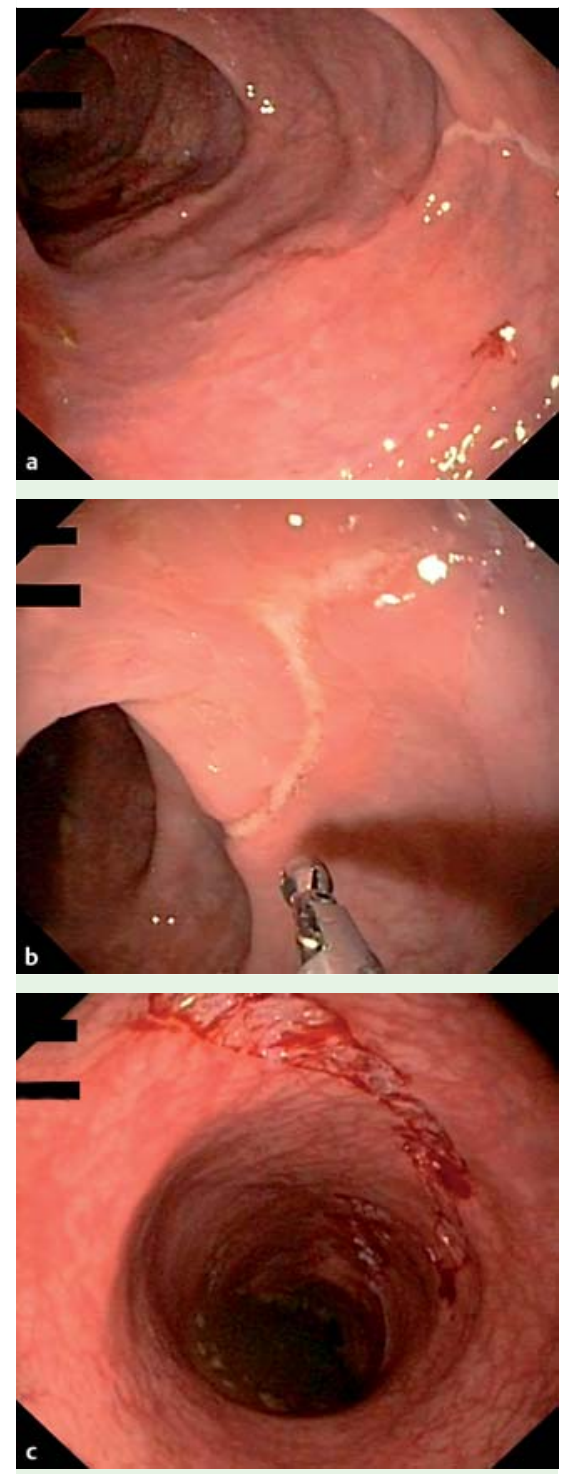

Fig. 1 Views during colonoscopy in 69-yearold woman with non-bloody diarrhea showing: a, b linear longitudinal mucosal tears; c fresh lacerations that appeared in the colonic mucosa during insufflation.

\section{Bibliography}

DOI http://dx.doi.org/

10.1055/s-0033-1359157

Endoscopy 2014; 46: E64

(c) Georg Thieme Verlag KG

Stuttgart · New York

ISSN 0013-726X

\section{Corresponding author \\ R. L. A. van Eijk, MD}

Gelderse Vallei Ziekenhuis Ede

Gastroenterology and Hepatology

Willy Brandtlaan 10

6716 RP Ede

The Netherlands

Fax: +31-8-435096

interneaaeijkr@zgv.nl 